\title{
Therapeutic Strategies with Synbiotics, Thalidomide, and Celecoxib for Severe COVID-19 Pneumonia
}

\author{
Masato Hada ${ }^{1}$ \\ ${ }^{1}$ Hada Clinic
}

June 11, 2020

\begin{abstract}
Dysregulation of proinflammatory cytokines promotes immune-mediated injuries. Epithelial-cell proliferation and an increase in lung macrophages have both been associated with the 2003 SARS-CoV infection. Proinflammatory cytokines as well as lipopolysaccharide and pathogen-associated molecular patterns (PAMPs) promote macrophage transition which promotes ongoing inflammation. PAMPs are primarily sensed by Toll-like receptors and/or by angiotensin-converting enzyme 2; this interaction serves to activate NF- $\varkappa$ B to promotes synthesis and secretion of proinflammatory cytokines. Activated immune cells secrete large amounts of specific proinflammatory cytokines including IL-1, IL-6, IL- 8 , TNF- $\alpha$, and TGF- $\beta 1$ which can promote severe lung injury. As such, immunomodulatory drugs alone may have an impact on the cytokine storm even without the addition of antiviral agents. The central transcription factor, NF- $\varkappa \mathrm{B}$, induces angiogenesis during cancer progression; combinations of pharmacological agents, including thalidomide and celecoxib, show promising results in cancer treatment studies. This may be due to a low-level, chronic cytokine storm similar to that described for acute and chronic hepatitis as well as for cirrhosis and hepatoma. As previously described, I have used thalidomide, celecoxib, and low dose cytotoxic agents since 2000 for the successful treatment of a variety of cancers. This regimen is cited or introduced in leading medical journals. Thalidomide is an immunomodulatory agent that modulates the activities of NF- $x \mathrm{~B}$ in combination with the cyclooxygenase-2 inhibitor, celecoxib. The combination of thalidomide and celecoxib might limit the inflammatory symptoms when used to treat severe COVID-19 pneumonia due to infection with SARS-CoV-2.
\end{abstract}

Clinical Review

Therapeutic Strategies with Synbiotics, Thalidomide, and Celecoxib forSevere COVID-19 Pneumonia

Short title: Treatment for severe COVID-19 pneumonia

Masato Hada, MD, Pharmacist

Hada Clinic, clinichada@cy.tnc.ne.jp

Corresponding author

Masato Hada, MD, Pharmacist (Medical Practitioner)

Hada Clinic, 1728-2 Oooka, Numazu City, Shizuoka Prefecture, Japan

Phone: +081559525779; FAX: +81559525779

E-mail address: clinichada@cy.tnc.ne.jp

Key words: proinflammatory cytokines, macrophages, SARS-CoV, thalidomide, celecoxib

Abbreviations used in this paper: 
PAMP: pathogen-associated molecular pattern

PRRs: pattern-recognition receptors

TLR: Toll-like receptor

SARS: severe acute respiratory syndrome

MERS: Middle East respiratory syndrome

NF- $\varkappa$ B: nuclear factor kappa B

IL: interleukin

TNF- $\alpha$ : tumor necrosis factor- $\alpha$

TGF- $\beta$ : Transforming growth factor- $\beta$

SARS-CoV: severe acute respiratory syndrome coronavirus

MERS-CoV: Middle East respiratory syndrome coronavirus

COVID-19: 2019 novel coronavirus

ACE2: angiotensin-converting enzyme 2

MyD88: myeloid differentiation factor 88

COX-2: cyclooxygenase-2

AMPK: AMP-activated protein kinase

VEGF: VEGF

bFGF: basic fibroblast growth factor

MCP-1: monocyte chemoattractant protein-1

iNOS: inducible nitric oxide synthase

\section{Summary}

Dysregulation of proinflammatory cytokines promotes immune-mediated injuries. Epithelial-cell proliferation and an increase in lung macrophages have both been associated with the 2003 SARS-CoV infection. Proinflammatory cytokines as well as lipopolysaccharide and pathogen-associated molecular patterns (PAMPs) promote macrophage transition which promotes ongoing inflammation. PAMPs are primarily sensed by Toll-like receptors and/or by angiotensin-converting enzyme 2 ; this interaction serves to activate NF- $\chi \mathrm{B}$ to promotes synthesis and secretion of proinflammatory cytokines. Activated immune cells secrete large amounts of specific proinflammatory cytokines including IL-1, IL-6, IL-8, TNF- $\alpha$, and TGF- $\beta 1$ which can promote severe lung injury. As such, immunomodulatory drugs alone may have an impact on the cytokine storm even without the addition of antiviral agents. The central transcription factor, NF- $\varkappa \mathrm{B}$, induces angiogenesis during cancer progression; combinations of pharmacological agents, including thalidomide and celecoxib, show promising results in cancer treatment studies. This may be due to a low-level, chronic cytokine storm similar to that described for acute and chronic hepatitis as well as for cirrhosis and hepatoma. As previously described, I have used thalidomide, celecoxib, and low dose cytotoxic agents since 2000 for the successful treatment of a variety of cancers. This regimen is cited or introduced in leading medical journals. Thalidomide is an immunomodulatory agent that modulates the activities of NF- $x \mathrm{~B}$ in combination with the cyclooxygenase- 2 inhibitor, celecoxib. The combination of thalidomide and celecoxib might limit the inflammatory symptoms when used to treat severe COVID-19 pneumonia due to infection with SARS-CoV-2.

\section{Introduction}


Coronavirus infection is typically associated with mild clinical symptoms, save for those due to infection with severe acute respiratory syndrome coronavirus (SARS-CoV) ${ }^{1}$, the Middle East respiratory syndrome coronavirus (MERS-CoV) ${ }^{2,3}$, and most recently, with SARS-CoV-2. An understanding of the pathophysiology of SARS-CoV-associated pneumonia induced will be helpful toward understanding the disease associated with the novel SARS-CoV-2 pathogen, a severe pneumonia known as Coronavirus Disease 2019 (2019-nCoV or COVID-19). Most of the published reports indicate that fatal COVID-19 has a clinical presentation that resembles that due to the original 2003 SARS-CoV pathogen. Most notably, in both cases, synthesis and release of proinflammatory cytokines has been associated with disease severity. Ongoing production can result in a cytokine storm and acute respiratory distress syndrome which are findings that can lead to fatal disease $^{4}$. Toll-like receptors (TLRs), NF- $\chi \mathrm{B}$, macrophages, and proinflammatory cytokines were all found to be involved in the development of severe pneumonia ${ }^{5}$.

\section{Toll-like Receptor Family}

As in the case of SARS-CoV, angiotensin-converting enzyme 2 (ACE2) has been identified as main host cell receptor of SARS-CoV-2 ${ }^{6}$. The ACE2 receptor was detected on cells from various human organs including lung alveolar epithelial cells and enterocytes of the small intestine. Interestingly, virus-activation of ACE2 can promote signaling and activation of NF- $\chi \mathrm{B}$ similar to that mediated by the TLRs ${ }^{7,8}$.

TLRs also play important roles with respect to the outcome of viral infection. TLRs play a central role in promoting innate immune responses via their interactions with PAMPs as pattern-recognition receptors (PRRs) both at the plasma membrane and within endosomes. Downstream signaling pathways of TLRs result in the activation of nuclear factor kappa $\mathrm{B}\left(\mathrm{NF}-\mathrm{xB}^{5}\right.$ mainly via signals transmitted through myeloid differentiation factor $88(\mathrm{MyD} 88)^{9}, 10,11,12$. Other factors involved in TLRs-mediated modulation of NF$x \mathrm{~B}$ are endosomal acidification ${ }^{13}$; activation of this pathway results in the production of proinflammatory cytokines and type I interferons. TLRs have been identified on B-lymphocytes, NK cells, dendritic cells, and macrophages, as well as on non-immune cells, including fibroblasts, epithelial cells and endothelial cells ${ }^{14,15}$. TLR3 may play a critical role in detecting RNA viruses and altering the pathogenesis of acute virus infection. Activation of this pathway may result in damage to alveolar and bronchial epithelial cells, as well as in various immune cells such as macrophages ${ }^{16}$. Bronchial epithelial cells and alveolar cells of lower respiratory tract express increasing amounts of TLR4 in response to inflammatory cell infiltration observed in response to coronavirus and other virus infections ${ }^{11,17}$. All TLR signaling pathways result in the activation NF- $x \mathrm{~B}$ which is the master regulator of inflammatory cytokine expression ${ }^{5}$.

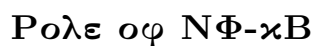

As there are no vaccines or conventional drugs available for the treatment of SARS-CoV-2, we might consider the possibility of using drugs that can suppress NF- $x \mathrm{~B}$ and thereby limit the inflammatory response to the virus pathogen ${ }^{18,19}$. NF- $\chi \mathrm{B}$ is a ubiquitous and pleiotropic protein that regulate more than 400 genes associated with the immune responses including inflammation, immunity, cell proliferation, differentiation, and survival ${ }^{20,21}$.

The canonical and non-canonical NF-қB signaling pathways differ with respect to downstream signaling involved in stress responses and for the regulation of cell proliferation and apoptosis; this provides a means for effective orchestration of inflammatory and immune responses ${ }^{22}$ and to modulate a number of different disorders including the inflammatory basis of metabolic diseases, glycolysis, and oxidative metabolism ${ }^{23}$. Therefore, NF- $x \mathrm{~B}$ could be a major target for therapeutic intervention ${ }^{24}$.

Virus-induced NF- $\chi \mathrm{B}$ activity can promote or suppress viral activity ${ }^{24,25,26}$. The initial immune response to viral infections includes the induction of numerous cytokines; TNF- $\alpha$ and IL- $1 \beta$ play key roles in the early induction of inflammation and innate immune responses ${ }^{27}$. Viral infections are controlled directly by TNF- $\alpha$. Moreover, these cytokines induce the synthesis and release of additional cytokines, promote the expression of cell adhesion molecules, and enhance the innate cytotoxicity of macrophages and neutrophils ${ }^{28}$. Moreover, activated NF-KB cause cytokine storm ${ }^{29}$. 


\section{Inflammatory Cytokines and Alveolar Epithelium}

The bronchial epithelium is a primary target for respiratory viruses ${ }^{28}$. Alveolar epithelium plays an important role in promoting cell barrier functions and strengthening cell-cell junctions against virusinduced disruption of tight junctions. However, virus infected epithelial cells express cytokines that primarily attract macrophages. Once recruited, the activated macrophages promote activation of adjacent endothelial cells. Infiltrating macrophages produce reactive oxygen species and nitric oxide ${ }^{30}$ that serve to damage the barrier $^{31}$. Macrophages also promote epithelial-cell apoptosis epithelial cells and mediate phagocytosis of apoptotic cells ${ }^{31,32,33}$.

\section{Synbiosis and Berberine}

Microbes in the gut play a central role in modulating immune responses, inflammation, and angiogenesis ${ }^{31}$. Microbial dysbiosis is an underlying factor in a variety of human disorders including metabolic diseases (obesity, type 2 diabetes mellitus), respiratory tract infections, appendicitis, and cardiovascular diseases ${ }^{34}$.The Gram-negative periodontal pathogen,Fusobacterium nucleatum plays an important role in promoting dysbiosis ${ }^{35}$. Alkalinized stomach contents due toHelicobacter pylori facilitate passage of microbes; likewise, cigarette smoking ${ }^{36}$ promotes the proliferation of anaerobic $F$. nucleatum which stimulates cells to produce proinflammatory cytokines, including IL-6, IL-8, and TNF $\alpha$ through TLRs ${ }^{37}$.

The actions of proinflammatory cytokines promote hypoxia, which results in the release HIF-1 that induces angiogenesis. Hypoxia itself leads to the production of proinflammatory cytokines via the NF- $x \mathrm{~B} / \mathrm{COX}-2$ pathway and thereby exacerbates local inflammatory conditions ${ }^{38}$.

Patients with underlying disorders that are caused by or related to dysbiosis are more susceptible to COVID19 , as they are primed to exacerbate the cytokine storm produced by both dysbiosis and virus infection ${ }^{7}$. Therefore, I suggest that synbiotics might be combined with thalidomide and celecoxib to generate an effective therapeutic regimen.

The combination of thalidomide and celecoxib is important as it will serve to suppresses the production of vascular endothelial growth factor (VEGF), basic fibroblast growth factor (bFGF) and COX-2, the three key mediators of angiogenesis ${ }^{39}$.

Synbiosis promoted by berberine will serve to limit the production of proinflammatory cytokines and promote the secretion of short chain fatty acids that are beneficial toward positive systemic immunomodulation. Berberine is an isoquinoline alkaloid purified from Japanese herb,Phellodendron amurense (known as KIHADA in Japanese) that is used for the treatment of microbe-associated diarrhea ${ }^{40}$. The anti-inflammatory activity of berberine involves activation of AMP-activated protein kinase (AMPK) ${ }^{41}$ and inhibition of NF- $\chi \mathrm{B}$ and AP-1 signaling pathways ${ }^{42}$. Berberine-mediated inhibition of these pathways limits both inflammation and carcinogenesis due to down-regulation of cytokines and proinflammatory enzymes, including TNF- $\alpha$, IL-1 $\beta$, IL-6, monocyte chemoattractant protein-1 (MCP-1), inducible nitric oxide synthase (iNOS), and COX $-2^{43,44}$. Patients with obesity, type 2 diabetes mellitus, hypertension, and/or a past history of acute appendicitis or $H$. pylori infection must be carefully observed while under this regimen.

\section{Treatment}

At present, there is no evidence from randomized controlled trials that supports the use of any specific drug regimen in patients with COVID-19. However, as I indicate here, there exist important common modalities

that link the virus-induced cytokine storm to malignancies, notably, both conditions result in overexpression of proinflammatory cytokines and angiogenesis factors via the activation of NF- $\chi \mathrm{B}^{24}$.

\section{Synbiotics}

Notably among mild COVID-19 patients, it will be important to maintain a healthy immune response with a favorable balance of intestinal microbes by introducing synbiotics which will address any issues associated with dysbiosis in the gastrointestinal tract of the host. The mechanism of action of synbiotics suggests that 
supplementation acts to promote probiotic-mediated reductions in NF- $x \mathrm{~B}$ activation and TNF- $\alpha$ production; in these cases, synbiotics function as immunomodulatory agents 45,46 .

\section{Berberine}

Berberine can contribute to the maintenance of healthy gut homeostasis together with probiotics and prebiotics ${ }^{47}$. Berberine is poorly water soluble and has low bioavailability; as such, it promotes few adverse events when introduced to the gut ${ }^{48,49} 50$.

\section{Thalidomide}

Thalidomide suppresses activated NF- $\chi \mathrm{B}$ that drives malignant cell proliferation, inflammation, angiogenesis, and poorly-regulated immune responses. ${ }^{51,52,53,54}$. Thalidomide also has an immunomodulatory effect when introduced together with the COX-2 inhibitor, celecoxib; together, these agents suppress the production of proinflammatory cytokines such as TNF- $\alpha$ and interleukin $-8^{55}$ through inhibition of NF- $x$ B by inhibiting the activity of the $\mathrm{I} \chi \mathrm{B}$ kinase ${ }^{56}$. Thalidomide may be a powerful drug for the treatment of severe COVID-19 pneumonia. Patients undergoing treatment with thalidomide must be under the careful supervision of the System for Thalidomide Education and Prescribing Safety (S.T.E.P.S.) program ${ }^{57}$.

\section{Celecoxib}

COX-2 is constitutively overexpressed in association with acute and chronic inflammation and also in malignant tumors ${ }^{58}$. Inflammation induced by pathogens and in response to disordered metabolic states such as obesity is associated with expression of COX $-2^{59}$. Prostaglandin and proinflammatory cytokine production is limited by COX-2 which results in a down-regulation of the cytokine storm ${ }^{60}$ and angiogenesis ${ }^{61,62,63}$. It is reported that celecoxib modulates $\mathrm{I} \chi \mathrm{B} \alpha$ degradation and phosphorylation and suppresses IKK activity in a dose-dependent manner ${ }^{64}$.

\section{Conclusion}

In conclusion, the combination of thalidomide and celecoxib together with an effort to maintain synbiosis with berberine are all important factors that may help mitigate the SARS-CoV-2-induced cytokine storm. In mild cases, one can focus on maintaining a healthy immune response via the administration of synbiotics. In moderate-to-severe cases, immunomodulatory agents and synbiotics, including berberine, may help to prevent the lethal cytokine storm ${ }^{60}$.

1. Thalidomide and Celecoxib

Low molecular weight immunomodulatory agents $(<350 \mathrm{Da})$ can cross the cell membrane and limit activation of NF-kB.

Thalidomide (200 mg/day), Celecoxib (400 mg/day)

2. Symbiotics and Berberine

Function by down-regulating proinflammatory cytokines

Funding: This research did not receive any specific grant from funding agencies in the public, commercial, or not-for-profit sectors.

\section{Conflict of Interests: None}

Ethics Approval: This is Review article - Ethics committee approval and informed consent are not needed.

\section{References}

1. Peiris JS, Guan Y, Yuen KY. Severe acute respiratory syndrome. Nat Med 2004; 10: S88-S97. PubMed Abstract/FullText 
2. Zaki AM, van Boheemen S, Bestebroer TM, Albert DME, Osterhaus DVM, Fouchier RAM. Isolation of a novel coronavirus from a man with pneumonia in Saudi Arabia. N Engl J Med 2012; 367: 1814-1820. PubMed Abstract/FullText

3. Lu R, Zhao X, Li J, Niu P, Yang B, Wu H, Wang W, Song H, et al. Genomic characterisation and epidemiology of 2019 novel coronavirus: Implications for virus origins and receptor binding. Lancet 2020 PubMed Abstract/FullText

4. Gu J, Korteweg C. Pathology and pathogenesis of severe acute respiratory syndrome. Am J Pathol 2007; 170: 1136-1147. PubMed PMC free article

5. Kawai T, Akira S. Signaling to NF-kappaB by toll-like receptors. Trends Mol Med 2007; 13: 460-469. PubMed Abstract/FullText

6. Ciaglia E, Vecchione C, Puca AA. COVID-19 infection and circulating ACE2 levels: Protective role in women and children. Front Pediatr 2020; 8: 206. PMC free article

7. Guo YR, Cao QD, Hong ZS, Tan YY, Chen SD, Jin HJ, Tan KS, Wang DY, et al. The origin, transmission and clinical therapies on coronavirus disease 2019 (COVID-19) outbreak-an update on the status. Mil Med Res 2020; 7: 11. PubMed PMC free article

8. Hamming I, Timens W, Bulthuis ML, Lely AT, Navis G, van Goor H. Tissue distribution of ACE2 protein, the functional receptor for SARS coronavirus. A first step in understanding SARS pathogenesis. J Pathol 2004; 203: 631-637. PubMed PMC free article

9. O'Neill LA, Bowie AG. The family of five: TIR-domain-containing adaptors in Toll-like receptor signalling. Nat Rev Immunol 2007; 7: 353-364. PubMed

10. Carty M, Bowie AG. Recent insights into the role of toll-like receptors in viral infection. Clin Exp Immunol 2010; 161: 397-406. PubMed PMC free article

11. Totura AL, Whitmore A, Agnihothram S, Schäfer A, Katze MG, Heise MT, Baric RS. Toll-like receptor 3 signaling via TRIF contributes to a protective innate immune response to severe acute respiratory syndrome coronavirus infection. mBio 2015; 6: e00638-15. PubMed PMC free article

12. Yamamoto M, Sato S, Mori K, Hoshino K, Takeuch O, Takeda K, Akira S. Cutting edge: A novel Toll/IL-1 receptor domain-containing adapter that preferentially activates the IFN- $\beta$ promoter in the toll-like receptor signaling. J Immunol 2002; 169: 6668-6672. Abstract/FullText

13. Hu YB, Dammer EB, Ren RJ, Wang G. The endosomal-lysosomal system: from acidification and cargo sorting to neurodegeneration. Transl Neurodegener 2015; 4: 18. PubMed PMC free article

14. Hamada A, Torre C, Drancourt M, Ghigo E. Trained immunity carried by non-immune cells. Front Microbiol 2019; 9: 3225. PubMed PMC free article

15. Wang R, Ahmed J, Wang G, Hassan I, Strulovici-Barel Y, Salit J, Mezey J, Crystal RG. Airway epithelial expression of toll-like receptor 5 is down-regulated in healthy smokers and smokers with chronic obstructive pulmonary disease. J Immunol 2012; 189: 2217-2225. PMC free article

16. Guillot L, Le Goffic R, Bloch S, Escriou N, Akira S, Chignard M, Si-Tahar M. Involvement of toll-like receptor 3 in the immune response of lung epithelial cells to double-stranded RNA and influenza A virus. J Biol Chem 2005; 280: 5571-5580. PubMed Abstract/FullText

17. Lafferty EI, Qureshi ST, Schnare M. The role of toll-like receptors in acute and chronic lung inflammation. J Inflamm (Lond) 2010; 7: 57. PMC free article

18. DeDiego ML, Nieto-Torres JL, Regla-Nava JA, Jimenez-Guardeño JM, Fernandez-Delgado R, Fett C, Castaño-Rodriguez C, Perlman S, et al. Inhibition of NF- $x \mathrm{~B}-$ mediated inflammation in severe acute 
respiratory syndrome coronavirus-infected mice increases survival. J Virol 2014; 88: 913-924. PubMed PMC free article

19. Vitiello M, Galdiero M, Finamore E, Galdiero S, Galdiero M. NF- $x$ B as a potential therapeutic target in microbial diseases. Mol Biosyst 2012; 8:1108-1120. PubMed

20. Hayden MS, West AP, Ghosh S. NF-kappaB and the immune response. Oncogene 2006; 25: 6758-6780. PubMed Abstract/FullText

21. Baud V, Karin M. Is NF- $x \mathrm{~B}$ a good target for cancer therapy? Hopes and pitfalls. Nat Rev Drug Discov 2009; 8: 33-40. PubMed PMC free article

22. Sun SC. Non-canonical NF- $x$ B signaling pathway. Cell Res. 2011; 21: 71-85. PubMed PMC free article

23. Londhe P, Yu PY, Ijiri Y, Ladner KJ, Fenger JM, London C, Houghton PJ, Guttridge DC. Classical NF- $x$ B metabolically reprograms sarcoma cells through regulation of hexokinase 2. Front Oncol 2018; 8: 104. PubMed PMC free article

24. Panday A, Inda ME, Bagam, P, Sahoo A, Osorio D, Batra S. Transcription factor NF- $x$ B: An update on intervention strategies. Arch Immunol Ther Exp (Warsz) 2016; 64: 463-483. Abstract

25. Schmitz ML, Kracht M, Saul VV. The intricate interplay between RNA viruses and NF-Kb. Biochim Biophys Acta 2014; 1843: 2754-2764. Abstract/FullText

26. Zhao J, He S, Minassian A, Li J, Feng P. Recent advances on viral manipulation of NF- $x \mathrm{~B}$ signaling pathway. Curr Opin Virol 2015; 15: 103-111. Abstract/FullText

27. Kany S, Vollrath JT, Relja B. Cytokines in inflammatory disease. Int J Mol Sci 2019; 20: 6008. PMC free article

28. Meusel TR, Imani F. Viral induction of inflammatory cytokines in human epithelial cells follows a p38 mitogen-activated protein kinase-dependent but NF-kappa B-independent pathway. J Immunol 2003; 171: 3768-3774. PubMed Abstract/FullText

29. Coperchini F, Chiovato L, Croce L, Magri F, Rotondi M. The Cytokine storm in COVID-19: An overview of the involvement of the chemokine/chemokine-receptor system. Cytokine Growth Factor Rev 2020. Abstract/FullText

30. Hor-Yue Tan, Ning Wang, Sha Li, Hong M, Wang X, Feng Y. The reactive oxygen species in macrophage polarization: Reflecting its dual role in progression and treatment of human diseases. Oxid Med Cell Longev 2016; 2016: 2795090. Abstract/FullText

31. Whisner CM, Athena Aktipis C. The role of the microbiome in cancer initiation and progression: how microbes and cancer cells utilize excess energy and promote one another's growth. Curr Nutr Rep 2019; 8: 42-51. PubMed Abstract/FullText

32. Short KR, Kroeze EJBV, Fouchier RAM, Kuiken T. Pathogenesis of influenza-induced acute respiratory distress syndrome. Lancet Infect Dis 2014; 14: 57-69. Abstract

33. Gregory CD, Devitt A. The macrophage and the apoptotic cell: an innate immune interaction viewed simplistically? Immunology 2004; 113: 1-14. PMC free article

34. Cani PD, Jordan BF. Gut microbiota-mediated inflammation in obesity: a link with gastrointestinal cancer. Nat Rev Gastroenterol Hepatol 2018; 15: 671-682. PubMed

35. Han YW. Fusobacterium nucleatum: a commensal-turned pathogen. Curr Opin Microbiol 2015; 23: 141-147. PubMed PMC free article

36. Shchipkova AY, Nagaraja HN, Kumar PS. Subgingival microbial profiles of smokers with periodontitis. J Dent Res 2010; 89: 1247-1253. PubMed PMC free article 
37. Park SR, Kim DJ, Han SH, Kang MJ, Lee JY, Jeong YJ, Lee SJ, Kim TH, et al. Diverse toll-like receptors mediate cytokine production by Fusobacterium nucleatum and Aggregatibacter actinomycetemcomitans in macrophages. Infect Immun 2014; 82: 1914-1920. PubMed PMC free article

38. Naldini A, Carraro F. Role of inflammatory mediators in angiogenesis. Curr Drug Targets Inflamm Allergy 2005; 4: 3-8. PubMed PDF

39. Gallo O, Franchi A, Magnelli L, Sardi I, Vannacci A, Boddi V, Chiarugi V, Masini E. Cyclooxygenase-2 pathway correlates with VEGF expression in head and neck cancer. Implications for tumor angiogenesis and metastasis. Neoplasia 2001; 3: 53-61. PubMed PMC free article

40. Neag MA, Mocan A, Echeverría J, Pop RM, Bocsan CI, Crişan G, Buzoianu AD. Berberine: Botanical occurrence, traditional uses, extraction methods, and relevance in cardiovascular, metabolic, hepatic, and renal disorders. Front Pharmacol. 2018; 9: 557. PubMed PMC free article

41. Li W, Hua B, Saud SM, Lin H, Hou W, Matter MS, Jia L, Colburn NH, et al. Berberine regulates AMP-activated protein kinase signaling pathways and inhibits colon tumorigenesis in mice. Mol Carcinog 2015; 54: 1096-1009. PubMed PMC free article

42. Wang H, Zhu C, Ying Y, Luo L, Huang D, Luo Z. Metformin and berberine, two versatile drugs in treatment of common metabolic diseases. Oncotarget 2017; 9: 10135-10146. PubMed PMC free article

43. Jeong HW, Hsu KC, Lee JW, Ham M, Huh JY, Shin HJ, Kim WS, Kim JB. Berberine suppresses proinflammatory responses through AMPK activation in macrophages. Am J Physiol Endocrinol Metab 2009; 296: E955-E964. PubMed Abstract/FullText

44. Zou K, Li Z1, Zhang Y, Zhang H, Li B, Zhu W, Shi J, Jia Q, Li Y. Advances in the study of berberine and its derivatives: a focus on anti-inflammatory and anti-tumor effects in the digestive system. Acta Pharmacol Sin 2017; 38: 157-167. PubMed PMC free article

45. Markowiak P, Śliżewska K. Effects of probiotics, prebiotics, and synbiotics on human health. Nutrients 2017; 9: pii: E1021. PubMed PMC free article

46. Eslamparast T, Poustchi H, Zamani F, Sharafkhah M, Malekzadeh R, Hekmatdoost A. Synbiotic supplementation in nonalcoholic fatty liver disease: A randomized, double-blind, placebo-controlled pilot study. Am J Clin Nutr 2014; 99: 535-542. PubMed Abstract/FullText

47. Zhang X, Zhao Y, Zhang M, Pang X, Xu J, Kang C, Li M, Zhang C, et al. Structural changes of gut microbiota during berberine-mediated prevention of obesity and insulin resistance in high-fat diet-fed rats. PLoS One 2012; 7: e42529. PubMed Abstract/FullText

48. Yu YN, Yu TC, Zhao HJ, Sun T, Chen H, Chen H, An H, Weng Y, et al. Berberine may rescue Fusobacterium nucleatum-induced colorectal tumorigenesis by modulating the tumor microenvironment. Oncotarget 2015; 6: 32013-32026. PubMed PMC free article

49. Mirhadi E, Rezaee M, Malaekeh-Nikouei B. Nano strategies for berberine delivery, a natural alkaloid of Berberis. Biomed Pharmacother 2018; 104: 465-473. PubMed

50. Feng R, Shou JW, Zhao ZX, He C, Ma C, Huang M, Fu J, Tan X, et al. Transforming berberine into its intestine-absorbable form by the gut microbiota. Sci Rep 2015; 5: 12155. PMC free article

51. Majumdar S, Lamothe B, Aggarwal BB. Thalidomide suppresses NF- $x$ B activation induced by TNF and $\mathrm{H}_{2} \mathrm{O}_{2}$, but not that activated by ceramide, lipopolysaccharides, or phorbol ester. J Immunol 2002; 168: 2644-2651. PubMed Abstract/FullText

52. Davis DW, Herbst RS, Abbruzzese JL. Antiangiogenic cancer therapy; CRC Press Book. Conventional Therapeutics with Antiangiogenic Activity page 301-327; page 316 Ref. 222 
53. Adamo V, Franchina T, Adamo B, Scandurra G, Scimone A. Brain metastases in patients with non-small cell lung cancer: focus on the role of chemotherapy. Ann Oncol 2006; 17: ii73-ii75. PubMed PDF

54. Tempfer CB, Schultheis B, Hilal Z, Dogan A, Rezniczek GA. Thalidomide and lenalidomide for recurrent ovarian cancer: A systematic review of the literature. Oncol Lett 2017: 14: 3327-3336. PubMed PMC free article

55. Gonzalez A, Sahaza JH, Ortiz BL, Restrepo A, Cano LE. Production of pro-inflammatory cytokines during the early stages of experimental Paracoccidioides brasiliensis infection. Med Mycol 2003; 41: 391-399. PubMed

56. Keifer JA, Guttridge DC, Ashburner BP, Baldwin AS. Inhibition of NF-kappa B activity by thalidomide through suppression of ikappaB kinase activity. J Biol Chem 2001; 276: 22382-22387.

57. Rehman W, Arfons LM, Lazarus HM. The rise, fall and subsequent triumph of thalidomide: lessons learned in drug development. Ther Adv Hematol. 2011; 2: 291-308. PubMed PMC free article

58. Pang LY, Hurst EA, Argyle DJ. Cyclooxygenase-2: A role in cancer stem cell survival and repopulation of cancer cells during therapy. Stem Cells Int 2016; 2016: 2048731. PubMed PMC free article

59. Chan PC, Liao MT, Hsieh PS. The dualistic effect of COX-2-mediated signaling in obesity and insulin resistance. Int J Mol Sci 2019; 20: 3115. PubMed PMC free article

60. Liu Q, Zhou Y, Yang Z. The cytokine storm of severe influenza and development of immunomodulatory therapy. Cell Mol Immunol 2016; 13: 3-10. Abstract/FullText

61. Maloney JP, Gao L. Proinflammatory cytokines increase vascular endothelial growth factor expression in alveolar epithelial cells. Mediators Inflamm 2015; 2015: 387842. PubMed PMC free article

62. Hada M, Mizutari K. A case of advanced pancreatic cancer with remarkable response to thalidomide, celecoxib and gemcitabine. Gan To Kagaku Ryoho 2004; 31: 959-961. PubMed

63. Hada M, Horiuchi T. A case report of chemotherapy with thalidomide, celecoxib and gemcitabine in the treatment of patients with brain metastases from lung cancer. No Shinkei Geka 2005; 33: 1021-1026. PubMed

64. Sareddy GR, Geeviman K, Ramulu C, Babu PP. The nonsteroidal anti-inflammatory drug celecoxib suppresses the growth and induces apoptosis of human glioblastoma cells via the NF- $x \mathrm{~B}$ pathway. J Neurooncol 2012; 106: 99-109. Abstract 